\title{
Covid-19 Kills More Men Than Women: An Overview of Possible Reasons
}

\author{
Annalisa Capuano ${ }^{1 *}$, Francesco Rossi ${ }^{1}$ and Giuseppe Paolisso ${ }^{2}$ \\ ${ }^{1}$ Department of Experimental Medicine, University of Campania Luigi Vanvitelli, Regional Centre of Pharmacovigilance, \\ Campania Region, Naples, Italy, ${ }^{2}$ Department of Advanced Medical and Surgical Sciences, University of Campania Luigi \\ Vanvitelli, Naples, Italy
}

The high mortality observed in Covid-19 patients may be related to unrecognized pulmonary embolism, pulmonary thrombosis, or other underlying cardiovascular diseases. Recent data have highlighted that the mortality rate of Covid-19 seems to be higher in male patients compared to females. In this paper, we have analyzed possible factors that may underline this sex difference in terms of activity of the immune system and its modulation by sex hormones, coagulation pattern, and preexisting cardiovascular diseases as well as effects deriving from smoking and drinking habits. Future studies are needed to evaluate the effects of sex differences on the prevalence of infections, including Covid-19, its outcome, and the responses to antiviral treatments.

OPEN ACCESS

Edited by:

Hendrik Tevaearai Stahel, Bern University Hospital, Switzerland

Reviewed by: Walter Malorni, Istituto Superiore di Sanità (ISS), Italy Maurizio Acampa,

Siena University Hospital, Italy

*Correspondence:

Annalisa Capuano annalisa.capuano@unicampania.it

Specialty section:

This article was submitted to General Cardiovascular Medicine, a section of the journal Frontiers in Cardiovascular Medicine

Received: 12 May 2020 Accepted: 26 June 2020 Published: 17 July 2020

Citation:

Capuano A, Rossi F and Paolisso G (2020) Covid-19 Kills More Men Than

Women: An Overview of Possible

Reasons.

Front. Cardiovasc. Med. 7:131. doi: 10.3389/fcvm.2020.00131
Keywords: Covid-19, mortality, gender difference, immune system, sex hormones, smoking habit, coagulation pattern, cardiovascular diseases

\section{INTRODUCTION}

All countries around the world are facing the COVID-19 emergency. As of June 22nd, more than $9,118,000$ people have contracted the disease, and deaths have exceeded $471,000^{1}$.

From a pathogenetic point of view, the progression of COVID-19 follows three main stages (1). The first stage, which approximately occurs in the initial 1-2 days, represents the phase in which the SARS-CoV-2 binds to epithelial cells and starts replicating. The human angiotensin-converting enzyme 2 (ACE2) receptor and TMPRSS2 are the main proteins involved in the cell entry of SARS-CoV-2 $(2,3)$. This phase is asymptomatic, and the innate immune response is limited. The second stage starts once the virus migrates down the respiratory tract. This phase is symptomatic with clear airway response and the innate immune response is triggered. An increase in the level of CXCL10 or other innate response cytokine is observed $(4,5)$. Indeed, this is the stage in which the so-called "cytokine storm" arises. Lastly, about $20 \%$ of patients with COVID-19 progress to a third stage, which is the most severe, and this stage is characterized by serious respiratory symptoms that include hypoxia, ground glass infiltrate, and progression to acute respiratory distress syndrome (ARDS). This stage can be further aggravated by organ failure and sepsis, potentially progressing to patient's death (6). At this stage, an aggressive immunomodulatory therapy is probably needed to prevent the onset of serious clinical consequences, such as the Disseminated intravascular coagulation (DIC) and the subsequent consumption coagulopathy (7). Indeed, as recently reported by a group of Italian researchers, the high mortality observed among Covid-19 patients may be somewhat due to unrecognized pulmonary embolism and pulmonary in situ thrombosis. Therefore, they suggested that a better understanding of Covid-19-related thromboembolic risk

\footnotetext{
${ }^{1}$ https://www.worldometers.info/coronavirus/ (accessed May 10, 2020).
} 
would help to optimize diagnostic strategies but also the proper pharmacological management of patients with Covid-19 (8).

Data shared by Global Health 50/50, an internationally selected company that promotes gender equality in healthcare, revealed a higher proportion of deaths for Covid-19 in men than women in almost all countries. In Italy, according to data reported in the bulletin of integrated surveillance (update of April 23rd, 2020), deaths in men are approximately double compared to that of women (17.1 vs. 9.3\%). Similar findings were reported in Greece, Holland, Denmark, Belgium, Spain, China, and the Philippines ${ }^{2}$. A study carried out by Liu et al. on 4,880 patients with respiratory symptoms or close contact with Covid-19 patients in a hospital in Wuhan showed that there was a significant higher rate in positivity to SARS-CoV2 in males and the elderly population ( $>70$ years), although only age was recognized as a risk factor (9). Similarly, a recent retrospective observational study showed that among critically ill patients with SARS-CoV-2, 67\% were males and that the mortality rate was higher in males (10). In addition, a review of data related to 1,099 patients with Covid-19 showed that $58.1 \%$ were males. Furthermore, out of 173 severe cases, $57.8 \%$ concerned this population too (11). In addition, recent published data from a survival analysis (12) showed that men had a significantly higher mortality and exhibited worse symptoms than women. Lastly, Scully et al. recently reported that the case fatality rate for males is 1.7 times higher than for females $(P<0.0001)(13)$.

Considering that sex differences are frequently observed in many diseases, responses to drugs and the occurrence of adverse drugs reactions (14-17) - and that many reasons may underline these differences-in this paper, we aim to provide an overview of factors, including those influencing the immune system response, that possibly underline the sex and gender differences observed in Covid-19 patients. All those factors are summarized in Table 1.

\section{SEX DIFFERENCES IN IMMUNE SYSTEM}

Many studies, both preclinical and clinical, have analyzed the role of the sex in immune response patterns during viral infections. Few studies have proposed that the sex variability in the prevalence, pathogenesis, and response to viral infections can be related to the greater humoral and cell-mediated immune responses of females to viral antigens (18-20). This variability is probably the driver of a lower intensity and prevalence of viral infections in females than males. Indeed, female patients seem to be less susceptible to viral infections due to intense and prolonged innate, humoral, and cell-mediated immune responses. The higher activity of innate immune system in women, which is mediated by Toll-like receptors, retinoic acid-inducible gene I-like receptors, and nucleotide oligomerization domain-like receptors, may lead to a faster and higher recognition of viral components and consequently higher production of type 1 interferon (IFN) and inflammatory cytokines (IL-1, TNFs) (21).

\footnotetext{
${ }^{2}$ https://www.epicentro.iss.it/coronavirus/sars-cov-2-differenze-genereimportanza-dati-disaggregati
}

TABLE 1 | Overview of sex- and gender-differences that could be responsible of increased mortality rate in men with Covid-19.
Activity of the immune system

Prevalence of cardiovascular diseases

Coagulation pattern

Smoking and drinking habits

Role of sex hormones
- Female patients seem to have an intense and prolonged innate, humoral, and cell-mediated immune response, leading to a faster and higher recognition of viral components might recover to a greater extent and are better protected from death during infections

- Testosterone shows suppressive effect on the immune function, while estrogen may have both suppressive and not suppressive effects depending on their levels

- In men androgens deficiency is associated with increased levels of inflammatory cytokines and increased CD4+/CD8+ T-cell ratio

- Estrogens are able to induce an upregulation in the expression of ACE2

- Exogenous estrogen increases the clotting risk in women and in biological males undergoing gender-affirming hormonal therapy

- Sex hormones could also affect the response to antiviral treatments or vaccines

- Women seem to have a higher risk and incidence of symptomatic supraventricular tachycardia and long QT syndrome compared with men

- Men show higher risk of atrial fibrillation and sudden cardiac death and they are more affected by atherosclerotic cardiovascular disease compared with women

- Men have a 3.6-fold higher risk of recurrent VTE than women

- Women show higher risk of VTE during fertile years

- Smoking habit is higher in men than women - Drinking habit is higher in men than women
- Preclinical studies showed that females

For instance, in the United States, the 1918 influenza pandemic was associated with a higher mortality rate in men than women (22). Male gender could also be associated with higher mortality rate in herpes simplex virus-1 (HSV-1) respiratory infection. Indeed, Brown et al. evaluated the effects of sex on susceptibility to HSV-1 respiratory infection after repeated exhaustive exercise (treadmill running at $36 \mathrm{~m} / \mathrm{min}$ ) in CD-1 mice ( 86 males and 89 females). The results showed that the exercise stress was associated with increased morbidity and mortality in male mice, while only an increase in morbidity was observed in females. Authors suggested that females might recover to a greater extent and are ultimately better protected from death (23). Similar findings were found by another preclinical study carried out by Han et al. (24), while no sex differences were found for ocular HSV-1 infection (25).

On the other hand, the higher immune responses observed in females may lead to increased development of symptoms of infection in this population (26). For instance, with regard to influenza A viruses, even though men seemed to be more exposed to this infection, women showed higher mortality rates 
(27). During $2009 \mathrm{H} 1 \mathrm{~N} 1$, a higher hospitalization rate was observed in young women (28). Furthermore, females had a 2fold higher risk of death than males $(29,30)$. This could be the consequence of the higher immune response that leads to high levels of pro-inflammatory cytokines, including IL-1, IL2, IL-6, G-CSF, IP-10, and TNF $\alpha$, a condition that is defined as a "cytokine storm" and that seems to worsen symptoms of Covid-19 infections, such as ARDS, organ failure, and sepsis $(31-33)$.

\section{The Role of Sex Hormones}

Apart from factors merely related to a higher/lower activity of innate, humoral, and cell-mediated immune responses and to the production of inflammatory cytokines, other factors, including sex hormones, may play a key role during response to viral infections (34). In women, the level of estrogen varies during the menstrual cycle and falls with menopause, while, in men, the level of testosterone remains stable up to 60 years of age. Sex hormones induce their effects through the binding with estrogen receptors $(\mathrm{ER} \alpha$ and $\mathrm{ER} \beta)$, the androgen receptor (AR), and progesterone receptors (PR-A and PRB). Innate immune cells express those receptors to varying degrees (35). Some studies have demonstrated that testosterone exhibits a suppressive effect on the immune function, while estrogen may have both suppressive or not suppressive effects depending on their levels (36-38). Data from studies carried out in humans revealed that in men androgens deficiency is associated with increased levels of inflammatory cytokines and increased $\mathrm{CD} 4+/ \mathrm{CD} 8+\mathrm{T}$-cell ratio compared to men with normal level of testosterone $(39,40)$. On the other hand, estrogens could affect several activities of the innate and adaptive immune responses, showing opposite effects on the immune system based on their level. Indeed, low doses of estrogens seem to induce monocyte differentiation into inflammatory DCs, leading to higher production of IL-4 and IFN- $\alpha$ and activate Th1-type and cell-mediated immune responses. On the contrary, high doses of estrogens show inhibitory activity on innate and pro-inflammatory immune responses and enhance Th2-type responses and humoral immune responses $(36,41)$. Given the multiple effects of female hormones on immune system functions, women may present different responses to viral infections during the course of their lives. For instance, during pregnancy, which represents a unique immunological state, women seem to undergo three different stages: an initial pro-inflammatory phase, a second one (corresponding to the second trimester of pregnancy), which is characterized by an anti-inflammatory state, and a third phase that is characterized by an increase of inflammatory processes, which are useful for uterine muscle contraction, for the delivery as well as for placenta rejection. The succession of these pro- and anti-inflammatory phases seems to be the results of T helper 1 (Th1)/T helper 2 (Th2) immune shifts that, in turn, could also reflect a change in sensitivity to infectious diseases among pregnant women (42). Indeed, the higher mortality rate of $2009 \mathrm{H} 1 \mathrm{~N} 1$ in women was found for those in reproductive age (20-49 years), suggesting a role of gonadal hormones, especially during pregnancy (28).
Lastly, sex hormones could also affect the response to antiviral treatments or vaccines. As reported by Klein (26), the efficacy of the HSV-2 vaccine and of the recombinant glycoprotein D (gD)-based HSV-2 vaccine against the development of symptoms associated with genital herpes was found to be higher in women than in men.

\section{SEX DIFFERENCE IN CARDIOVASCULAR DISEASES}

Recent literature data showed a higher prevalence of hypertension and coronary artery disease in patients with severe forms of Covid-19 (43,44), suggesting that preexisting cardiovascular diseases may lead to a worse prognosis. According to $\mathrm{Wu}$ et al. (45), an arrhythmogenic effect of Covid-19, with occurrence of long and short QT syndrome, Brugada syndrome, and catecholaminergic polymorphic ventricular tachycardia, could be expected (46). These life-threatening cardiac disorders can be the consequence of enhanced inflammation, which can increase the duration of ventricular repolarization, by affecting the QTc interval (47). On the other hand, heart injury can be induced by other mechanisms, including some deriving from the effects of ACE2 that is expressed in the lungs and in the cardiovascular system, while other deriving from the cytokine storm and hypoxaemia that results in myocardial cells damage ${ }^{3}$. Indeed, inflammatory cytokines, especially interleukin-6, increase the risk of QT interval prolongation and life-threatening arrhythmias (48). In addition, cytokines show a pro-atherogenic effect, including TNF- $\alpha$, which activates NF- $\kappa$, p38 MAPK, and the transcription of proinflammatory genes for cytokines involved in the cytokine storm (49). Therefore, the role of cytokines in worsening the cardiovascular homeostasis of patients with Covid-19 cannot be excluded.

Some sex differences have been found in the incidence of cardiovascular diseases. Indeed, while women seem to have a higher risk and incidence of symptomatic supraventricular tachycardia and long QT syndrome, men show higher risk of atrial fibrillation and sudden cardiac death. Furthermore, epidemiological studies demonstrated that men are more affected by atherosclerotic cardiovascular disease compared with women. This difference can be imputable to the clinical risk profile, effects of sex hormones, and social attitude (50). Apart from sex differences in the production of inflammatory cytokines and in the incidence of cardiovascular diseases, recent evidence shows that a sex difference in virus-targeted mechanism could be hypothesized. As previously reported, the ACE2 receptor is essential for the cell entry of SARS-CoV-2, but it also represents an important enzyme of the renin-angiotensin system (RAS) that provides protective effects in many chronic conditions, like hypertension, cardiovascular diseases, and acute respiratory distress syndrome. All these clinical conditions represent risk factors for a worse prognosis in Covid-19 patients. Ruggieri and Gagliardi have recently reported that estrogens are able to

\footnotetext{
${ }^{3}$ https://www.nature.com/articles/s41569-020-0360-5\#citeas
} 
induce an upregulation in the expression of ACE2, which could explain better outcome and lower death rate in women compared to men ${ }^{4}$. Furthermore, as recently reported by Gagliardi et al., the gene that encodes for ACE2 is on the $\mathrm{X}$ chromosome, and XX cells over-express it (51). Furthermore, the results of a preclinical study that investigated the role of ACE2 in angiotensin (1-7)-induced hypertension and regulation of the RAS system in the kidney of wild type and Ace2 knockout mice revealed some sex differences in rising of mean arterial pressure, binding of glomerular AT1 receptor, and renal protein expression of the neutral endopeptidase neprilysin, suggesting that females may be protected from angiotensin (1-7)-induced hypertension (52).

Even though the ACE2 plays an essential role in the RAS system, it should be highlighted that a recent retrospective cohort study, carried out on 4,480 patients with Covid-19, showed that the prior use of ACE inhibitors or angiotensin receptor blockers (both acting on RAS) was not significantly associated with COVID-19 diagnosis neither with mortality or severe disease (53).

\section{SEX DIFFERENCE IN COAGULATION PATTERN}

The DIC is a life-threatening syndrome which leads to disseminated and uncontrolled activation of coagulation, thrombosis, and progressive consumption coagulopathy, leading to an increased bleeding risk. The DIC occurs frequently in almost $30-50 \%$ of patients with sepsis and $10 \%$ in patients with solid tumors, trauma, or obstetric calamities. Furthermore, the risk of DIC is higher in critically ill patients hospitalized in ICU, for whom the prevalence of DIC is about $8.5-34 \%$ (54). According to Tang et al., $\sim 71.4 \%$ of the non-survivor patients with Covid-19 matched the grade of overt-DIC ( $\geq 5$ points) in later stages of SARS-Cov-2 pneumonia, and $76 \%$ of the non-survivors were males. On the contrary, only the $0.6 \%$ of survivors matched the DIC criteria during the hospital stay (55). Moreover, the DIC appears to be a driver of disease severity. As might be expected, it is a strong prognostic factor for poor outcome (55). Finally, microthrombi have been reported as autopsy findings in patients with Covid- $19^{5}$.

It is widely demonstrated that differential risks in men and women for cardiovascular disease exist, especially during premenopausal period due to female sex regulating hormones. Moreover, once reproductive risk factors are taken into account, men have a 3.6-fold higher risk of recurrent venous thromboembolism (VTE) than women (56). The pathophysiology behind this observation is unclear (57). Indeed, it is known that deficient coagulation problems, such as hemophilia, are under genetic control and sex-related, so one cannot exclude that hypercoagulability might be also affected by genetic factors (58). Furthermore, women

\footnotetext{
$\overline{{ }^{4} \text { https://www.gendermedjournal }}$.it/articoli.php?archivio=yes\&vol_id=3351\&id= 33219

${ }^{5}$ https://www.preprints.org/manuscript/202002.0407/v2
}

show higher risk of VTE during fertile years, mainly as consequence of the effects mediated by pregnancy and oral contraceptive use. In this regard, literature data suggested that exogenous estrogen increases the clotting risk in women and in biological males undergoing gender-affirming hormonal therapy $(59,60)$.

\section{GENDER DIFFERENCES IN SMOKING AND DRINKING HABITS}

Compared to non-smokers, smokers generally show higher rates of respiratory diseases, including colds, influenza, bacterial pneumonia, and tuberculosis (61-64). Indeed, smoking habit leads to progressive lung damage, which exposes patients to higher risk of pulmonary bacterial and viral infections (65). This leads to higher risk of hospitalization due to influenza infection as well (66). Lastly, smoking represents the fourth leading cause of death in the world (67). In the context of Covid-19, smokers are more likely to contract the disease since the act of smoking implies that possibly contaminated fingers are in contact with lips, increasing the possibility of the SARSCoV-2 virus being transmitted from hand to mouth $(68,69)$. Furthermore, smoking is also related to higher expression of ACE2, which is involved in the process of cell entry of the SARS-CoV-2 (70).

Generally, the percent of smoking habits is found to be higher in men than women, since the adolescent age, even though with differences among low- medium- and highincome countries $(71,72)$. In order to evaluate the association between smoking and Covid-19 outcomes, in terms of disease severity, need for mechanical ventilation or intensive care unit (ICU), hospitalization, and death, Vardavas et al. carried out a systematic review of studies on Covid-19 patients that included information on patients' smoking status. Authors highlighted that there were higher percentages of current and former smokers among patients who accessed to ICU, required mechanical ventilation, or who had died (73). Other studies are strongly needed to evaluate the prevalence of smokers among patients with severe Covid-19, but based on current knowledge it is possible to assume that smokers are likely to be at higher risk for severe SARS-CoV-2 infection. Therefore, smoking cessation awareness should be strongly encouraged in order to reduce the global impact of COVID-19 (74).

As for smoking habits, drinking is found to be higher in men than women. Indeed, women generally drink less and have a lower prevalence of drink problems than men (75). Alcohol-related liver disease represents one of the main causes of liver cirrhosis, associated with high mortality and morbidity. A recent study, which has analyzed the prevalence, severity and mortality of patients diagnosed with COVID-19 with underlying chronic liver diseases, showed that this disease is associated to higher severity and mortality also in Covid-19 patients ${ }^{6}$.

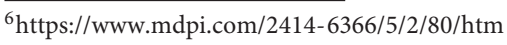




\section{CONCLUSION}

Covid-19 still represents a worldwide health emergency. In this paper, we have analyzed possible factors that may have contributed to a gender difference in Covid-19 clinical outcomes, especially in the rate of death. Among possible factors, those related to the activity of immune system and the role of sex hormones seem to be the most important. However, in our opinion, sex differences in cardiovascular diseases and coagulation patterns should be considered as well, especially considering the possible role of the cytokine storm in inducing vascular inflammation and atherosclerosisrelated cardiovascular diseases but also gender differences in coagulation, which can be responsible of higher risk of thrombotic/thromboembolic phenomena in men compared

\section{REFERENCES}

1. Mason RJ. Pathogenesis of COVID-19 from a cell biology perspective. Eur Respir J. (2020) 55:2000607. doi: 10.1183/13993003.00607-2020

2. Fehr AR, Perlman S. Coronaviruses: an overview of their replication and pathogenesis. Methods Mol Biol. (2015) 1282:123. doi: 10.1007/978-1-4939-2438-7_1

3. Hoffmann M, Kleine-Weber H, Schroeder S, Krüger N, Herrler T, Erichsen $\mathrm{S}$, et al. SARS-CoV-2 cell entry depends on ACE2 and TMPRSS2 and is blocked by a clinically proven protease inhibitor. Cell. (2020) 181: 271280.e8. doi: 10.1016/j.cell.2020.02.052

4. Qian Z, Travanty EA, Oko L, Edeen K, Berglund A, Wang J, et al. Innate immune response of human alveolar type II cells infected with severe acute respiratory syndrome-coronavirus. Am J Respir Cell Mol Biol. (2013) 48:7428. doi: 10.1165/rcmb.2012-0339OC

5. Wang J, Nikrad MP, Phang T, Gao B, Alford T, Ito Y, et al. Innate immune response to influenza A virus in differentiated human alveolar type II cells. Am J Respir Cell Mol Biol. (2011) 45:582-91. doi: 10.1165/rcmb.2010-0108OC

6. Guo YR, Cao QD, Hong ZS, Tan YY, Chen SD, Jin HJ, et al. The origin, transmission and clinical therapies on coronavirus disease 2019 (COVID-19) outbreak - an update on the status. Mil Med Res. (2020) 7:11. doi: 10.1186/s40779-020-00240-0

7. COVID-19 and Haemostasis: A Position Paper From Italian Society on Thrombosis and Haemostasis (SISET). Available online at: http://www.sah.org. ar/pdf/covid-19/083-20_pre-publishing.pdf

8. Lodigiani C, Iapichino G, Carenzo L, Cecconi M, Ferrazzi P, Sebastian T, et al. Venous and arterial thromboembolic complications in COVID-19 patients admitted to an academic hospital in Milan, Italy. Thromb Res. (2020) 191:9-14. doi: 10.1016/j.thromres.2020.04.024

9. Liu R, Han H, Liu F, Lv Z, Wu K, Liu Y, et al. Positive rate of RTPCR detection of SARS-CoV-2 infection in 4880 cases from one hospital in Wuhan, China, from Jan to Feb 2020. Clin Chim Acta. (2020) 505:1725. doi: 10.1016/j.cca.2020.03.009

10. Yang X, Yu Y, Xu J, Shu H, Xia J, Liu H, et al. Clinical course and outcomes of critically ill patients with SARS-CoV-2 pneumonia in Wuhan, China: a single-centered, retrospective, observational study. Lancet Respir Med. (2020) 8:475-481. doi: 10.1016/S2213-26002030079-5

11. Xie J, Tong Z, Guan X, Du B, Qiu H. Clinical characteristics of patients who died of coronavirus Disease 2019 in China. JAMA New Open. (2020) 3:e205619. doi: 10.1001/jamanetworkopen.2020.5619

12. Jin JM, Bai P, He W, Wu F, Liu XF, Han DM, et al. Gender differences in patients with COVID-19: focus on severity and mortality. Front Public Health. (2020) 8:152. doi: 10.3389/fpubh.2020.00152

13. Scully EP, Haverfield J, Ursin RL, Tannenbaum C, Klein SL. Considering how biological sex impacts immune responses and COVID-19 outcomes. Nat Rev Immunol. (2020) 20:442-7. doi: 10.1038/s41577-020-0348-8 to women. Further epidemiological studies will be needed to confirm this. Lastly, considering that women are often underrepresented in randomized clinical trials, future studies are needed to evaluate the effects of sex differences on the prevalence of infections, their outcome, and responses to antiviral treatments.

\section{AUTHOR CONTRIBUTIONS}

AC, FR, and GP drafted the work and revised it for important intellectual content, made substantial contributions to the acquisition, analysis, or interpretation of data for the work, approved the final version of the manuscript, developed the concept, and wrote the manuscript. All authors contributed to the article and approved the submitted version.
14. Ferrajolo C, Sultana J, Ientile V, Scavone C, Scondotto G, Tari M, et al. Gender Differences in outpatient pediatric drug utilization: a cohort study from Southern Italy. Front Pharmacol. (2019) 10:11. doi: 10.3389/fphar.2019. 00011

15. Sessa M, Mascolo A, Scavone C, Perone I, Di Giorgio A, Tari M, et al. Comparison of long-term clinical implications of beta-blockade in patients with obstructive airway diseases exposed to beta-blockers with different $\beta 1$ adrenoreceptor selectivity: an Italian Population-Based Cohort Study. Front Pharmacol. (2018) 9:1212. doi: 10.3389/fphar.2018.01212

16. Scavone C, Di Mauro C, Ruggiero R, Bernardi FF, Trama U, Aiezza ML, et al. Severe cutaneous adverse drug reactions associated with allopurinol: an analysis of spontaneous reporting system in Southern Italy. Drugs Real World Outcomes. (2020) 7:41-51. doi: 10.1007/s40801-019-00174-7

17. Corrao S, Santalucia P, Argano C, Djade CD, Barone E, Tettamanti M, et al. Gender-differences in disease distribution and outcome in hospitalized elderly: data from the REPOSI study. Eur J Intern Med. (2014) 25:61723. doi: 10.1016/j.ejim.2014.06.027

18. Klein SL, Jedlicka A, Pekosz A. The Xs and $\mathrm{Y}$ of immune responses to viral vaccines. Lancet Infect Dis. (2010) 10:33849. doi: 10.1016/S1473-3099(10)70049-9

19. Khandaker G, Dierig A, Rashid H, King C, Heron L, Booy R. Systematic review of clinical and epidemiological features of the pandemic influenza A (H1N1) 2009. Influenza Other Respir Viruses. (2011) 5:148-56. doi: 10.1111/j.1750-2659.2011.00199.x

20. Puchhammer-Stockl E, Aberle SW, Heinzl H. Association of age and gender with alphaherpesvirus infections of the central nervous system in the immunocompetent host. J Clin Virol. (2012) 53:356-9. doi: 10.1016/j.jcv.2011.12.015

21. Ruggieri A, Gagliardi MC, Anticoli S. Sex-dependent outcome of hepatitis B and $\mathrm{C}$ viruses infections: synergy of sex hormones and immune responses? Front Immunol. (2018) 9:2302. doi: 10.3389/fimmu.2018.02302

22. Noymer A. The 1918 influenza pandemic affected sex differentials in mortality: Comment on Sawchuk. Am J Phys Anthropol. (2010). 143:499500. doi: 10.1002/ajpa.21405

23. Brown AS, Davis JM, Murphy EA, Carmichael MD, Ghaffar A, Mayer EP. Gender differences in viral infection after repeated exercise stress. Med Sci Sports Exerc. (2004) 36:1290-5. doi: 10.1249/01.MSS.0000135798.72735.B3

24. Han $X$, Lundberg $P$, Tanamachi $B$, Openshaw $H$, Longmate J, Cantin E. Gender influences herpes simplex virus type 1 infection in normal and gamma interferon-mutant mice. J Virol. (2001) 75:3048-52. doi: 10.1128/JVI.75.6.3048-3052.2001

25. Riccio RE, Park SJ, Longnecker R, Kopp SJ. Characterization of sex differences in ocular herpes simplex virus 1 infection and herpes stromal keratitis pathogenesis of wild-type and herpesvirus entry mediator knockout mice. mSphere. (2019) 4:e0073-19. doi: 10.1128/mSphere.0 0073-19 
26. Klein SL. Sex influences immune responses to viruses, and efficacy of prophylaxis and treatments for viral diseases. Bioessays. (2012) 34:10509. doi: 10.1002/bies.201200099

27. Klein SL, Pekosz A, Passaretti C, Anker M, Olukoya P. Sex, Gender and Influenza. Geneva: World Health Organization (2010). p. 1-58.

28. Klein SL, Passaretti C, Anker M, Olukoya P, Pekosz A. The impact of sex, gender and pregnancy on 2009 H1N1 disease. Biol Sex Differ. (2010) 1:5. doi: 10.1186/2042-6410-1-5

29. Randolph AG, Vaughn F, Sullivan R, Rubinson L, Thompson BT, Yoon G, et al. Critically ill children during the 2009-2010 influenza pandemic in the United States. Pediatrics. (2011) 128:e1450-8. doi: 10.1542/peds.2011-0774d

30. Zarychanski R, Stuart TL, Kumar A, Doucette S, Elliott L, Kettner J, et al. Correlates of severe disease in patients with 2009 pandemic influenza (H1N1) virus infection. CMAJ. (2010) 182:257-64. doi: 10.1503/cmaj.091884

31. Capuano A, Scavone C, Racagni G, Scaglione F, Italian Society of Pharmacology. NSAIDs in patients with viral infections, including Covid-19: victims or perpetrators? Pharmacol Res. (2020) 157:104849. doi: 10.1016/j.phrs.2020.104849

32. Scavone C, Brusco S, Bertini M, et al. Current pharmacological treatments for COVID-19: what's next? Br J Pharmacol. (2020) 1-12. doi: 10.1111/bph.15072

33. di Mauro G, Scavone C, Rafaniello C, Rossi F, Capuano A. SARSCov-2 infection: response of human immune system and possible implications for the rapid test and treatment. Int Immunopharmacol. (2020) 84:106519. doi: 10.1016/j.intimp.2020.106519

34. Roved J, Westerdahl H, Hasselquist D. Sex differences in immune responses: hormonal effects, antagonistic selection, and evolutionary consequences. Horm Behav. (2017) 88:95-105. doi: 10.1016/j.yhbeh.2016.11.017

35. Kadel S, Kovats S. Sex Hormones regulate innate immune cells and promote sex differences in respiratory virus infection. Front Immunol. (2018) 9:1653. doi: 10.3389/fimmu.2018.01653

36. Khan D, Ansar Ahmed S. The immune system is a natural target for estrogen action: opposing effects of estrogen in two prototypical autoimmune diseases. Front Immunol. (2016) 6:635. 10.3389/fimmu.2015.00635

37. Foo YZ, Nakagawa S, Rhodes G, Simmons LW. The effects of sex hormones on immune function: a meta-analysis. Biol Rev Camb Philos Soc. (2017) 92:551-71. doi: 10.1111/brv.12243

38. Trigunaite A, Dimo J, Jørgensen TN. Suppressive effects of androgens on the immune system. Cell Immunol. (2015) 294:87-94. doi: 10.1016/j.cellimm.2015.02.004

39. Malkin CJ, Pugh PJ, Jones RD, Kapoor D, Channer KS, Jones TH. The effect of testosterone replacement on endogenous inflammatory cytokines and lipid profiles in hypogonadal men. J Clin Endocrinol Metab. (2004) 89:3313-8. doi: 10.1210/jc.2003-031069

40. Bobjer J, Katrinaki M, Tsatsanis C, Lundberg Giwercman Y, Giwercman A. Negative association between testosterone concentration and inflammatory markers in young men: a nested cross-sectional study. PLoS ONE. (2013) 8:e61466. doi: 10.1371/journal.pone.0061466

41. Seillet C, Laffont S, Trémollières F, Rouquié N, Ribot C, Arnal JF, et al. The TLR-mediated response of plasmacytoid dendritic cells is positively regulated by estradiol in vivo through cell-intrinsic estrogen receptor $\alpha$ signaling. Blood. (2012) 119:454-64. doi: 10.1182/blood-2011-08-371831

42. Mor G, Cardenas I. The immune system in pregnancy: a unique complexity. Am J Reprod Immunol. (2010) 63:42533. doi: 10.1111/j.1600-0897.2010.00836.x

43. Guan WJ, Ni ZY, Hu Y, Liang W, Ou C, He J, et al. Clinical characteristics of coronavirus disease 2019 in China. N Engl J Med. (2020) 382:170820. doi: 10.1056/NEJMoa2002032

44. Wang D, Hu B, Hu C, Zhu F, Liu X, Zhang J, et al. Clinical characteristics of 138 hospitalized patients with 2019 novel coronavirus-infected pneumonia in Wuhan, China. JAMA. (2020) 323:1061-9. doi: 10.1001/jama.2020.1585

45. Wu CI, Postema PG, Arbelo E, Behr ER, Bezzina CR, Napolitano C, et al. SARS-CoV-2, COVID-19, and inherited arrhythmia syndromes. Heart Rhythm. (2020) S1547-5271(20)30285-X. doi: 10.1016/j.hrthm.2020.03.024

46. Baldi E, Sechi GM, Mare C, Canevari F, Brancaglione A, Primi R et al. Outof-hospital cardiac arrest during the Covid-19 outbreak in italy. $N$ Engl J Med. (2020) NEJMc2010418. doi: 10.1056/NEJMc2010418. [Epub ahead of print].
47. Lazzerini PE, Boutjdir M, Capecchi PL. COVID-19, arrhythmic risk and inflammation: mind the gap!. Circulation. (2020). doi: 10.1161/CIRCULATIONAHA.120.047293

48. Aromolaran AS, Srivastava U, Alí A, Chahine M, Lazaro D, El-Sherif $\mathrm{N}$, et al. Interleukin-6 inhibition of hERG underlies risk for acquired long QT in cardiac and systemic inflammation. PLoS ONE. (2018) 13:e0208321. doi: 10.1371/journal.pone.0208321

49. Welsh P, Grassia G, Botha S, Sattar N, Maffia P. Targeting inflammation to reduce cardiovascular disease risk: a realistic clinical prospect? Br J Pharmacol. (2017) 174:3898-913. doi: 10.1111/bph.13818

50. Tian J, Wang X, Tian J, Yu B. Gender differences in plaque characteristics of nonculprit lesions in patients with coronary artery disease. BMC Cardiovasc Disord. (2019) 19:45. doi: 10.1186/s12872-019-1023-5

51. Gagliardi MC, Tieri P, Ortona E, Ruggieri A. ACE2 expression and sex disparity in COVID-19. Cell Death Discov. (2020) 6:37. doi: 10.1038/s41420-020-0276-1

52. Ji H, de Souza AMA, Bajaj B, Zheng W, Wu X, Speth RC, et al. Sex-specific modulation of blood pressure and the renin-angiotensin system by ACE (Angiotensin-Converting Enzyme) 2. Hypertension. (2020). doi: 10.1161/HYPERTENSIONAHA.120.15276

53. Fosbøl EL, Butt JH, Østergaard L, Andersson C, Selmer C, Kragholm K, et al. Association of angiotensin-converting enzyme inhibitor or angiotensin receptor blocker use with COVID-19 diagnosis and mortality. JAMA. (2020) e2011301. doi: 10.1001/jama.2020.11301

54. Papageorgiou C, Jourdi G, Adjambri E, Walborn A, Patel P, Fareed J, et al. Disseminated intravascular coagulation: an update on pathogenesis, diagnosis, and therapeutic strategies. Clin Appl Thromb Hemost. (2018) 24(9 Suppl.):1076029618806424. doi: 10.1177/1076029618806424

55. Tang N, Li D, Wang X, Sun Z. Abnormal coagulation parameters are associated with poor prognosis in patients with novel coronavirus pneumonia. J Thromb Haemost. (2020) 18:844-7. doi: 10.1111/jth.14768

56. Tagalakis V. Sex may matter when it comes to the presenting location of deep vein thrombosis. Thromb Res. (2019) 173:1645. doi: 10.1016/j.thromres.2018.12.001

57. Roach RE, Cannegieter SC, Lijfering WM. Differential risks in men and women for first and recurrent venous thrombosis: the role of genes and environment. J Thromb Haemost. (2015) 12:1593-600. doi: 10.1111/jth.12678

58. Bushnell CD. Stroke and the female brain. Nat Clin Pract Neurol. (2008) 4:22-33. doi: 10.1038/ncpneuro0686

59. Bischof E, Wolfe J, Klein SL. Clinical trials for COVID-19 should include sex as a variable. J Clin Invest. (2020) 130:3350-3352. doi: 10.1172/JCI139306

60. Getahun D, Nash R, Flanders WD, Baird TC, Becerra-Culqui TA, Cromwell L, et al. Cross-sex hormones and acute cardiovascular events in transgender persons: a cohort study. Ann Intern Med. (2018) 169:205213. doi: 10.7326/M17-2785

61. Atto B, Eapen MS, Sharma P, Frey U, Ammit AJ, Markos J, et al. New therapeutic targets for the prevention of infectious acute exacerbations of COPD: role of epithelial adhesion molecules and inflammatory pathways. Clin Sci. (2019) 133:1663-703. doi: 10.1042/CS20181009

62. Eapen MS, Sharma P, Moodley YP, Hansbro PM, Sohal SS. Dysfunctional immunity and microbial adhesion molecules in smoking-induced pneumonia. Am J Respir Crit Care Med. (2019) 199:250-1. doi: 10.1164/rccm.201808-1553LE

63. Eapen MS, Sharma P, Sohal SS. Mitochondrial dysfunction in macrophages: a key to defective bacterial phagocytosis in COPD. Eur Respir J. (2019) 54:1901641. doi: 10.1183/13993003.01641-2019

64. Eapen MS, Sohal SS. Understanding novel mechanisms of microbial pathogenesis in chronic lung disease: implications for new therapeutic targets. Clin Sci. (2018) 132:375-9. doi: 10.1042/CS20171261

65. Lawrence H, Hunter A, Murray R, Lim WS, McKeever T. Cigarette smoking and the occurrence of influenza-Systematic review. J Infect. (2019) 79:4016. doi: 10.1016/j.jinf.2019.08.014

66. Han L, Ran J, Mak YW, Suen LK, Lee PH, Peiris JSM, et al. Smoking and influenza-associated morbidity and mortality: a systematic review and meta-analysis. Epidemiology. (2019) 30:405-17. doi: 10.1097/EDE.0000000000000984 
67. World Health Organisation Chronic Obstructive Pulmonary Disease (COPD). (2020). Available online at: https://www.who.int/respiratory/copd/en/ (accessed March, 11 2020)

68. Istituto Superiore di Sanità. Tobacco Smoking in the Age of COVID-19. Available online at: https://www.epicentro.iss.it/en/coronavirus/sars-cov-2addictions-smoking

69. Cai H. Sex difference and smoking predisposition in patients with COVID-19. Lancet Respir Med. (2020) 8:e20. doi: 10.1016/S2213-260020 30117-X

70. Li J, Zhang Y, Wang F, Liu B, Li H, Tang G, et al. Sex differences in clinical findings among patients with coronavirus disease 2019 (COVID-19) and severe condition. medRxiv. (2020) 02.27.20027524. doi: 10.1101/2020.02.27.200 27524

71. Zeman MV, Hiraki L, Sellers EM. Gender differences in tobacco smoking: higher relative exposure to smoke than nicotine in women. J Womens Health Gend Based Med. (2002) 11:147-53. doi: 10.1089/152460902753 645281

72. Han J, Chen X. A Meta-analysis of cigarette smoking prevalence among adolescents in China: 1981-2010. Int J Environ Res Public Health. (2015) 12:4617-30. doi: 10.3390/ijerph120504617
73. Vardavas CI, Nikitara K. COVID-19 and smoking: a systematic review of the evidence. Tob Induc Dis. (2020) 18:20. doi: 10.18332/tid/119324

74. Komiyama M, Hasegawa K. Smoking cessation as a public health measure to limit the coronavirus disease 2019 pandemic. Eur Cardiol. (2020) 15:e16. doi: 10.15420/ecr.2020.11

75. Ely M, Hardy R, Longford NT, Wadsworth ME. Gender differences in the relationship between alcohol consumption and drink problems are largely accounted for by body water. Alcohol Alcohol. (1999) 34:894902. doi: 10.1093/alcalc/34.6.894

Conflict of Interest: The authors declare that the research was conducted in the absence of any commercial or financial relationships that could be construed as a potential conflict of interest.

Copyright (c) 2020 Capuano, Rossi and Paolisso. This is an open-access article distributed under the terms of the Creative Commons Attribution License (CC BY). The use, distribution or reproduction in other forums is permitted, provided the original author(s) and the copyright owner(s) are credited and that the original publication in this journal is cited, in accordance with accepted academic practice. No use, distribution or reproduction is permitted which does not comply with these terms. 